\title{
Update of the budget impact analysis of the simplification to atazanavir + ritonavir + lamivudine dual therapy of HIV-positive patients receiving atazanavir-based triple therapies in Italy starting from data of the Atlas-M trial
}

This article was published in the following Dove Press journal:

ClinicoEconomics and Outcomes Research

27 September 2017

Number of times this article has been viewed

\section{Umberto Restelli',2 \\ Massimiliano Fabbiani ${ }^{3}$ \\ Simona Di Giambenedetto ${ }^{3}$ \\ Carmela Nappi ${ }^{4}$ \\ Davide Croce ${ }^{1,2}$ \\ 'Center for Health Economics, Social and Health Care Management, LIUC - Università Cattaneo, Castellanza, Italy; ${ }^{2}$ School of Public Health, Faculty of Health Sciences, University of the Witwatersrand, Johannesburg, South Africa; ${ }^{3}$ nstitute of Clinical Infectious Diseases, Catholic University of Sacred Heart, ${ }^{4} \mathrm{Health}$ Economics, Bristol Myers Squibb S.r.l., Rome, Italy}

Correspondence: Umberto Restelli Center for Health Economics, Social and Health Care Management, LIUC Università Cattaneo, Corso Matteotti 22, 21053, Castellanza, VA, Italy

Tel +39033I 572346

Fax +390331572513

Email urestelli@gmail.com
In 2017, the authors published an article to assess the financial consequences for the Italian National Health Service, over a 5-year period, of the adoption of a simplification strategy to atazanavir (ATV) + ritonavir (r) + lamivudine (3TC) dual therapy of HIVpositive patients receiving ATV plus two nucleoside reverse transcriptase inhibitors (NRTIs) starting from data of the Atlas-M trial at 48 weeks. ${ }^{1}$

Consequently to the publication of the clinical results of the Atlas-M trial at 96 weeks, we updated the model implemented for the analysis, considering the most recent evidence. ${ }^{2}$

The model was adapted considering the transitions among antiretroviral therapies (ARTs) observed in the trial, as reported in Figure 1, for years 1 and 2, and maintaining for years 3, 4, and 5 the same differential effectiveness (percentage of patients without virologic failure) observed between 48 and 96 weeks. In detail, the percentage of virologic failures considered in year 1 were $4.51 \%$ for ATV $+r+2$ NRTI and $0.76 \%$ for ATV+r+3TC; and in each following year were $8.66 \%$ for ATV+r+2 NRTI and $3.05 \%$ for ATV+r+3TC.

The costs considered (referred to year 2016) are direct medical costs related to ART, adverse events management, and follow-up, in terms of drugs, hospitalizations, laboratory tests, and outpatient activities. The same criteria to identify the target population (comprising 1,892 patients, with 33 incident cases each year) and the same hypotheses on the number of patients eligible to ART simplification per year of the previous analysis were considered. Therefore, a base case scenario was implemented in which the simplification strategy is not applied, along with three scenarios in which the number of patients assigned each year to ATV $+\mathrm{r}+3 \mathrm{TC}$ simplification were half of the eligible patients (scenario 1), one third of the eligible patients (scenario 2), and one fifth of the eligible patients (scenario 3).

The updated analysis confirmed the order of magnitude of the results of the analysis that considered the Atlas-M trial results at 48 weeks, as reported in Table 1.

The likely 5-year impact on the budget of the Italian National Health Service of the simplification strategy considered for the target population is between -26.3 million $€(-32.1 \%)$ in scenario 1 and -14.2 million $€(-17.4 \%)$ in scenario 3 . The adoption of 


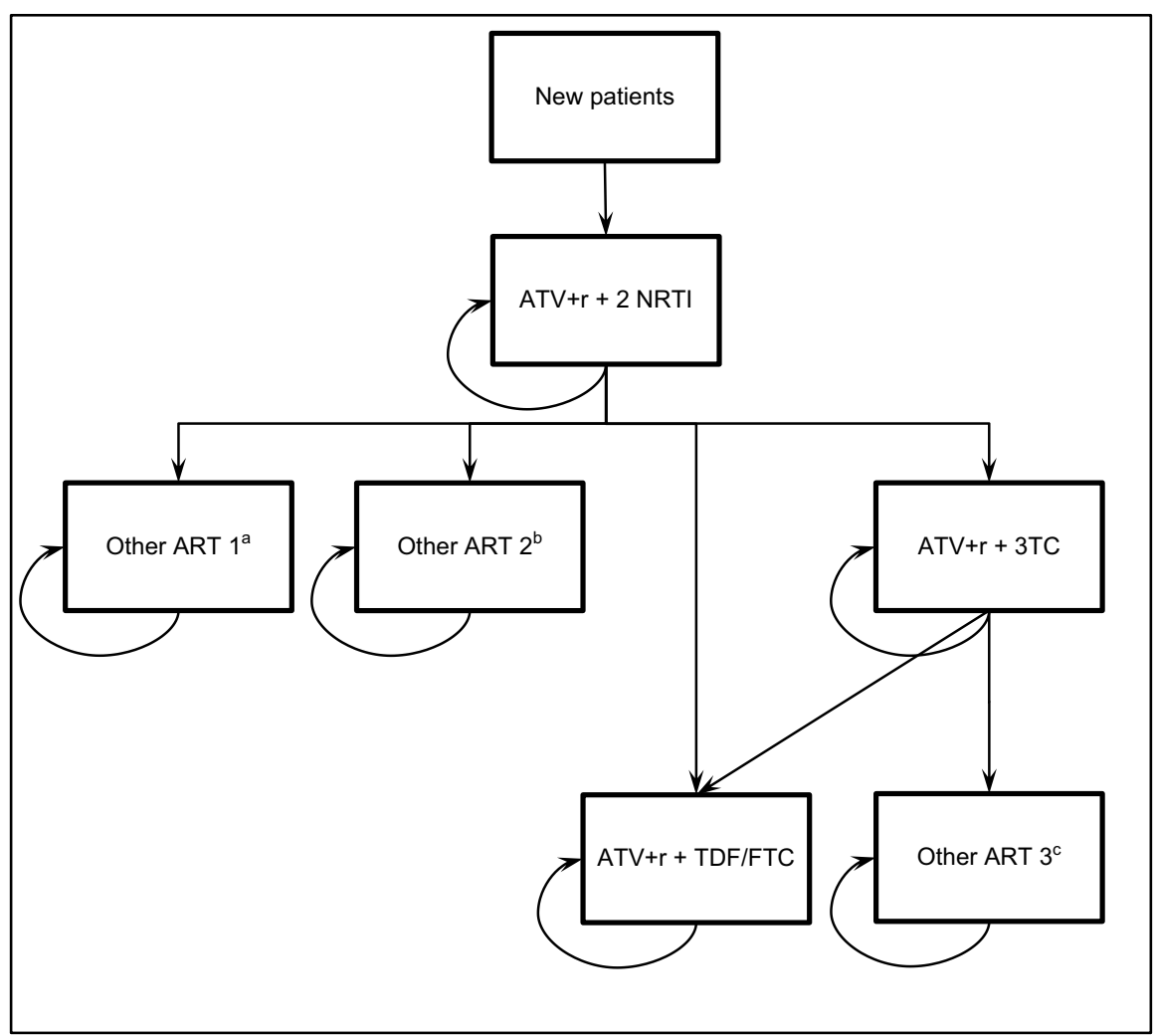

Figure I Structure of the budget impact model.

Note: ${ }^{a}$ Other ART I: 100\% TDF/FTC/C/EVG. 'Other ART 2: 28.6\% TDF/FTC+RAL; I4.3\% ABC/3TC/DTG; I4.3\% TDF/FTC/c/EVG; I4.3\% 3TC/DTG; I4.3\% ABC/3TC/NVP; 14.3\% ABC/3TC/DRV+r. 'Other ART 3: 25\% TDF/FTC/RPV; $25 \%$ ABC/3TC/DRV+r; $50 \%$ DRV+r.

Abbreviations: 3TC, lamivudine; ABC, abacavir; ART, antiretroviral therapy; ATV, atazanavir; c, cobicistat; DRV, darunavir; DTG, dolutegravir; EVG, elvitegravir; FTC, emtricitabine; NRTI, nucleoside reverse transcriptase inhibitor; NVP, nevirapine; $r$, ritonavir; RAL, Raltegravir; RPV, rilpivirine; TDF, tenofovir.

Table I Results of the budget impact analysis

\begin{tabular}{|c|c|c|c|c|c|c|}
\hline \multirow[t]{2}{*}{ Scenario } & \multicolumn{6}{|c|}{ Annual cost (million $€$ ) } \\
\hline & Year I & Year 2 & Year 3 & Year 4 & Year 5 & Total \\
\hline Base case & 16.1 & 16.3 & 16.4 & 16.5 & 16.6 & 82.0 \\
\hline Scenario I & 12.6 & 11.2 & 10.7 & 10.6 & 10.6 & 55.6 \\
\hline Difference between scenario I and base case (\% impact) & $\begin{array}{l}-3.6 \\
(-22.1 \%)\end{array}$ & $\begin{array}{l}-5.1 \\
(-31.5 \%)\end{array}$ & $\begin{array}{l}-5.7 \\
(-35.0 \%)\end{array}$ & $\begin{array}{l}-5.9 \\
(-35.9 \%)\end{array}$ & $\begin{array}{l}-5.9 \\
(-35.9 \%)\end{array}$ & $\begin{array}{l}-26.3 \\
(-32.1 \%)\end{array}$ \\
\hline Scenario 2 & 13.8 & 12.5 & 11.8 & $\mathrm{II} .4$ & 11.3 & 60.8 \\
\hline Difference between scenario 2 and base case (\% impact) & $\begin{array}{l}-2.4 \\
(-14.7 \%)\end{array}$ & $\begin{array}{l}-3.8 \\
(-23.3 \%)\end{array}$ & $\begin{array}{l}-4.6 \\
(-28.0 \%)\end{array}$ & $\begin{array}{l}-5.0 \\
(-30.6 \%)\end{array}$ & $\begin{array}{l}-5.3 \\
(-32.0 \%)\end{array}$ & $\begin{array}{l}-21.1 \\
(-25.8 \%)\end{array}$ \\
\hline Scenario 3 & 14.7 & 13.9 & 13.4 & 13.0 & 12.7 & 67.7 \\
\hline Difference between scenario 3 and base case (\% impact) & $\begin{array}{l}-1.4 \\
(-8.8 \%)\end{array}$ & $\begin{array}{l}-2.4 \\
(-14.8 \%)\end{array}$ & $\begin{array}{l}-3.1 \\
(-18.6 \%)\end{array}$ & $\begin{array}{l}-3.5 \\
(-21.3 \%)\end{array}$ & $\begin{array}{l}-3.8 \\
(-23.2 \%)\end{array}$ & $\begin{array}{l}-14.2 \\
(-17.4 \%)\end{array}$ \\
\hline
\end{tabular}

the simplification strategy in all the scenarios considered would lead to a yearly increase of the minor costs observed compared with the base case scenario, from -3.6 million $€$ in year 1 to -5.9 million $€$ in year 5 in scenario 1 ; from -2.4 million $€$ in year 1 to -5.3 million $€$ in year 5 in scenario 2 ; and from -1.4 million $€$ in year 1 to -3.8 million $€$ in year 5 in scenario 3 .

Therefore, the updated analysis confirmed the results of the previous analysis, showing that the simplification strategy from ATV+r+2NRTI to ATV $+\mathrm{r}+3 \mathrm{TC}$ is associated with a decrease in the direct medical costs in the Italian context for the treatment of the target population without impact on the clinical effectiveness of ART.

\section{Acknowledgments}

We would like to thank the Atlas-M Study Group for their contribution in sharing the clinical Atlas-M data. The analysis was supported by an unconditional grant from Bristol Myers Squibb. 


\section{Disclosure}

UR declares speaker fees (Janssen Cilag, Abbvie, Gilead). MF received speakers' honoraria and support for travel to meetings from Bristol Myers Squibb, Gilead, Merck Sharp \& Dohme, ViiV Healthcare, and Janssen-Cilag. SDG declares speakers' honoraria and support for travel to meetings from Bristol Myers Squibb, Gilead, Merck Sharp \& Dohme, ViiV Healthcare, and Janssen-Cilag. CN is employed by Bristol Myers Squibb S.r.l. DC declares advisory board fees (Merck Sharp \& Dohme, Abbvie). The authors report no other conflicts of interest in this work.

\section{References}

1. Restelli U, Fabbiani M, Di Giambenedetto S, Nappi C, Croce D. Budget impact analysis of the simplification to atazanavir + ritonavir + lamivudine dual therapy of HIV-positive patients receiving atazanavir-based triple therapies in Italy starting from data of the Atlas-M trial. Clinicoecon Outcomes Res. 2017;9:173-179. Erratum in: Clinicoecon Outcomes Res. 2017;9:231.

2. Gagliardini R, Fabbiani M, Quiros Roldan E, et al. Simplification to atazanavir/ritonavir lamivudine versus maintaining atazanavir/ritonavir 2NRTIs in virologically suppressed HIV-infected patients: 96-week data of the ATLAS-M trial. Glasgow Congress on HIV Therapy, 23-26 October 2016. Oral abstract O121.
ClinicoEconomics and Outcomes Research

\section{Publish your work in this journal}

ClinicoEconomics and Outcomes Research is an international, peerreviewed open-access journal focusing on health technology assessment, pharmacoeconomics and outcomes research in the areas of diagnosis, medical devices, and clinical, surgical and pharmacological intervention. The economic impact of health policy and health systems

\section{Dovepress}

organization also constitute important areas of coverage. The manuscript management system is completely online and includes a very quick and fair peer-review system, which is all easy to use. Visit http://www.dovepress.com/testimonials.php to read real quotes from published authors.

Submit your manuscript here: https://www.dovepress.com/clinicoeconomics-and-outcomes-research-journal 